\title{
Winning the war against anaphylaxis requires continued professional patient manegement till discharge
}

\author{
Ozan Kocak ${ }^{1}$, Mahir Igde ${ }^{2}$ \\ 1-Ozan Kocak, MD, Department of Pediatric Neurology, Turkish Health Sciences University, Samsun Training Hospital, Samsun, Turkey. E-mail: \\ ozankocak79@gmail.com \\ 2-Mahir İgde, MD, Associate Professor, Department of Pediatric Allergy-Immunology, Turkish Health Sciences University, Samsun Training \\ Hospital, Samsun, Turkey. E-mail: drmahirigde@gmail.com \\ Correspondence: Ozan Kocak, Adalet Mah., Lise Cad. No:83, Samsun Kadin Dogum Ve Cocuk Hastanesi Ilkadım/Samsun, Turkey 55070; Phone: + \\ 90 5057916232; E-mail: ozankocak79@gmail.com
}

\section{Abstract}

Objective: Anaphylaxis and anaphylactic shock are not alien to the anesthesiologists. Many anesthetics and even non-enesthetic drugs used in the hospitals may teigger it. Successful management extends even beyond the initial recovery. The aim of this study was to determine the current knowledge of the doctors of different specialities concerning the management of anaphylaxis after diagnosis till discharge of the patient.

Methodology: A total of 750 doctors from assorted specialties were assessed and this survey based descriptive study was conducted between June 2019 and October 2019. Participantss were asked to describe the approach after first diagnosis till the discharge time. In this way the tasks to be completed after the diagnosis in an anaphylaxis case were enquired.

We used a 10-question survey, developed by using primarily World Allergy Organiztion (WAO) questionare guideline. In all the questions, multiple answers and free text comments were asked.

Results: The level of knowledge of each participant was calculated for a total of ten questions. The correct answer ratio showed that doctors had significant knowledge gaps related to management of anaphylaxis after the first intervention. The total knowledge score index (KSI) score was found to be $41.55 \pm 15.91$; judged to be very low.

No correlation was found between KSI and the age of doctors ( $p>0.05)$, or duration of practice $(p>0.05)$, or having attended or not any episode of anaphylaxis. However, there was significant difference in mean KSI according to the time of last update of information about anaphylaxis $(p<0.05)$.

Conclusion: The study data confirm that the knowledge and the awareness of healthcare staff about the importance of the subsequent continued management of anaphylaxis after the initial steps needs to be enhanced. Repeated interval reeducation seems to be important to solve this problem.

Key words: Anaphylaxis; Management; Education

Citation: Kocak $\mathrm{O}$, İgde $\mathrm{M}$. Winning the war against anaphylaxis requires continued professional patient manegement till discharge. Anaesth. pain intensive care 2020;24(4):411-419.

Received: 21 May 2020, Reviewed: 30 May 2020, Accepted: 10 June 2020

\section{Introduction}

Anaphylaxis is a life-threatening systemic reaction affecting all age groups. ${ }^{1}$ High rates of hospitalization for anaphylaxis have been reported in different countries of the world. ${ }^{2}$ The cases of anaphylaxis might have to be managed by doctors from different specialities. Before the international guidelines were developed, a worldwide lack of essential skills for the diagnosis and treatment of anaphylaxis was documented. ${ }^{3}$ This potentially fatal condition requires immediate intervention and follow-up. ${ }^{4}$ Adrenaline administration has been the first-line intervention after diagnosis. ${ }^{5}$ Several guidelines have recently been 
released in an effort to alleviate this global health concern; emphasizing the importance of the provision of adrenaline auto-injectors (AAIs), appropriate counselling and education of the patients (and caregivers where relevant) and of doctors. ${ }^{6}$ Still anaphylaxis related fatality rates have remained stable or decreased only slightly even after several amendments in the treatment protocols. There remains a paucity of data regarding approach after diagnosis and urgent treatment of anaphylaxis. There is significant potential for this information to influence policy making regarding management of allergic reactions and to provide insight into risks to allergic patients.

The allergy testing needs to be performed following the guidelines. ${ }^{7}$ It is aimed to prevent new admissions to the emergency department, prevent fatal events, provide every patient at risk for anaphylaxis with selfinjectable adrenaline, education, action plan, medical ID stating trigger factors, perform an exhaustive allergic workup, to reach an accurate diagnosis and risk assessment, identify and report patients at risk to ED network, and to perform continuing education for health professionals.

Concerns about poor knowledge of the front-line medical staff about the prompt recognition and management of anaphylaxis have been raised. It may be also be true about management after the initial treatment. We believe that more emphasis is needed on appropriate treatment of anaphylaxis by healthcare professionals. And in this study, we have tried to focus on this topic.

\section{Methodology}

A total of 750 doctors were assessed and the study was conducted between June 2019 and October 2019 at hospitals in Samsun, Turkey.

The survey was shared via a social media site in a closed group of verified physicians with identity card as members. Physicians who volunteered, were invited to study and asked to complete a short questionnaire. The range of doctors approached in each of the hospitals is shown in Figure 1. Data were collected using Google Forms and then analysed in SPSS version 22.0.

The survey was designed by a pediatric allergist as a 10-item questionnaire by using WAO questionare
Box 1: Questionnaire consisting of 10 questions Q1. What is your first choice of treatment for anaphylaxis?

A1.

Q2. What is the giving route of the first drug?

A2.

Q3. When is the first drug given after anaphylaxis diagnosis?

A3.

Q4. In which position patient with anaphylaxis should the followed?

A4.

Q5. What should we pay attention before discharging patients of anaphylaxis? And, what should be our recommendations? (Give six options) A5.

A6.

A7.

A8.

A9.

A10.

guideline. ${ }^{3}$ The participants were asked to describe the approach and actions to be taken after first diagnosis till to discharge time.

Participants were asked to respond to all questions if they were active in their clinical practice. In all openended questions, free text comments were asked. The questionnaire is shown in Box 1.

Because the survey was designed as open ended, in the survey responses, the existence of expected correct answers were searched. The answers were evaluated by two ways. First each question was analyzed separately according to being false and true, secondly by giving ten points to each correct answer, the level of knowledge of each participant was calculated over hundred for a total of ten questions.

Ethics committee approval was deemed unnecessary, as the survey was an evaluation of current practice using nonidentifiable case scenario. Completion of the questionnaire implied consent for this process.

\section{Results}

A total of 750 physicians from twenty-nine different specialities and 12 different hospitals of Samsun were included in the study (Figure 1). According to patients contact points with doctors in healthcare system of 
Figure 1: Distribution of doctors according to their expertise

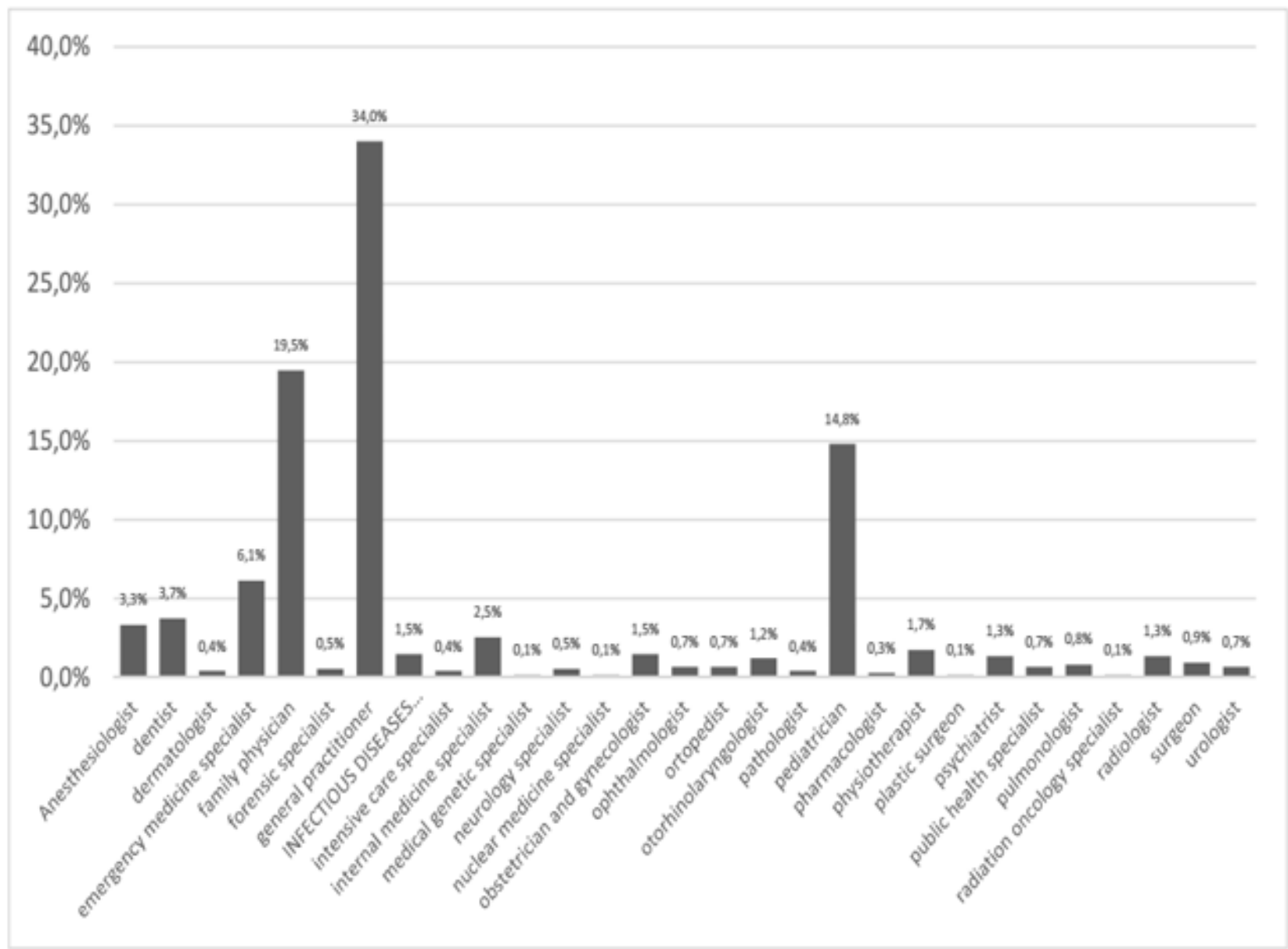

Turkey, we grouped the doctors as; primary care group ( $\mathrm{n}=148$, family medicine physcians), emergency group ( $\mathrm{n}=298$, general practioners and emergency medicine physcians) and others from other secondary care and tertiary care disciplines $(\mathrm{n}=304)$.

We also focused on demographic data (e.g., number of years in practice, age group, specialty area, number of years of last update on anaphylaxis knowledge). This data is presented as Table 1.

We evaluated the answers to the questions in two ways, separately and together (Table 2).

In our questionnaire;

First and the central question: "What is the responding physician's first-line drug when treating anaphylaxis?". All groups similarly answered the question mostly as "adrenalin" (88.7\%) $(\mathrm{p}>0.05)$.

But to our 2nd question: "What is the route of administration?" we found significant differences in correct answer percentage $(p=0001)$ between the
Table 1: Sociodemographic characteristics $(n=750)$

\begin{tabular}{|c|c|}
\hline Variable & Data \\
\hline Age, years (mean $\pm S D$ ) & $35.281 \pm 7.9935$ \\
\hline $\begin{array}{l}\text { Years in practice } \\
\text { (mean } \pm \text { SD) }\end{array}$ & $10.477 \pm 7.9879$ \\
\hline \multicolumn{2}{|c|}{$\begin{array}{l}\text { When did you last update your information } \\
\text { about anaphylaxis? }\end{array}$} \\
\hline Last one year & $428(57.1 \%)$ \\
\hline Last $2-3$ years & $141(18.8 \%)$ \\
\hline More than 3 years & $181(24.1 \%)$ \\
\hline \multicolumn{2}{|c|}{ Have you attended any episode of anaphylaxis? } \\
\hline Yes & $407(54.3 \%)$ \\
\hline No & $343(45.7 \%)$ \\
\hline
\end{tabular}

groups. The percentage of correct answer (it should be intramuscular; is $63.5 \%$ for all participants) dropped dramatically, especially among the primary and the secondary care doctors $(53.6 \%)$ (Table 3 ). 
Table 2: Survey evaluation

\begin{tabular}{|c|c|c|c|}
\hline No. & Questions & Correct answer & Score \\
\hline 1. & $\begin{array}{l}\text { What is your first choice of } \\
\text { treatment for anaphylaxis? }\end{array}$ & adrenaline & 10 \\
\hline 2. & $\begin{array}{l}\text { What is the giving route of the } \\
\text { first drug? }\end{array}$ & intramuscular & 10 \\
\hline 3. & $\begin{array}{l}\text { When is the first drug given after } \\
\text { anaphylaxis diagnosis? }\end{array}$ & As soon as possible after diagnosis & 10 \\
\hline 4. & $\begin{array}{l}\text { In which position patient with } \\
\text { anaphylaxis should the followed? }\end{array}$ & $\begin{array}{l}\text { They should be placed on the back with their lower } \\
\text { extremities elevated or, if they are experiencing respiratory } \\
\text { distress or vomiting, they should be placed in a position of } \\
\text { comfort with their lower extremities elevated. }\end{array}$ & 10 \\
\hline 5. & \multirow{6}{*}{$\begin{array}{l}\text { What should we pay attention } \\
\text { before discharging patients of } \\
\text { anaphylaxis? And, what should } \\
\text { be our recommendations? }\end{array}$} & $\begin{array}{l}\text { Because of anaphylaxis recurrence and biphasic } \\
\text { anaphylaxis risk, after apparent resolution of symptoms, } \\
\text { duration of monitoring in a medically supervised setting } \\
\text { should be individualized. }\end{array}$ & 10 \\
\hline 6. & & $\begin{array}{l}\text { Epinephrine/adrenaline auto-injector or Epinephrine from } \\
\text { an ampule/syringe or prefilled syringe }\end{array}$ & 10 \\
\hline 7. & & $\begin{array}{l}\text { Anaphylaxis emergency action plan (personalized, written) } \\
\text { and Medical record electronic flag (or chart sticker) }\end{array}$ & 10 \\
\hline 8. & & Medical identification (e.g., bracelet, wallet card)/ & 10 \\
\hline 9. & & $\begin{array}{l}\text { Long-term risk reduction: avoidance and/or } \\
\text { immunomodulation }\end{array}$ & 10 \\
\hline 10. & & $\begin{array}{l}\text { Emphasize the importance of follow-up, preferably with an } \\
\text { allergy/immunology specialist }\end{array}$ & 10 \\
\hline \multicolumn{3}{|c|}{ Total score } & 100 \\
\hline
\end{tabular}

Third question: "When the treatment should begin after anaphylaxis diagnosis?" All three groups answer the question correctly in similar manner: [as soon as possible] $(91.7 \%, \mathrm{p}<0.05)$ (Table 3).

Fourth question: "During treatment, in which position the patient should be followed?". Answer should be [be placed on the back with their lower extremities elevated or, if they were experiencing respiratory distress or vomiting, they should be placed in a position of comfort with their lower extremities elevated]. Right Answers percentage of this question of in which position the patient should be followed during treatment, were similar among doctors of different care steps $(62.7 \%, \mathrm{p}<0.05)$ (Table 3).

Next six questions were about: "What should we pay attention to before discharging patients of anaphylaxis? And, what should be our recommendations". We compared the responses by different doctor groups. While evaluating the answers, we investigated the inclusion of six points of vital importance.
These are described here (Table 3);

5. Evaluation of the risk of anaphylaxis relapse before discharge: average true answer percentage existence was found $6.3 \%$, but groups true answer ratios were found significantly different from each other $(\mathrm{p}=$ 0.001). Highest true answer percentage was found among emergency care doctors' group (10.1\%).

6. Prescribing adrenaline auto-injectors during discharge: average true answer percentage existence is found $25.3 \%$, but groups true answer ratios were found significantly different from each other $(p=0.001)$. Highest true answer percentage was found among secondary care doctors' group (32.2\%).

7. Anaphylaxis grade to the medical file and the preparation of anaphylaxis action plan: average true answer percentage existence is found $11.2 \%$, groups true answer ratios are found similar each other $(\mathrm{p}=$ 0.257 )

8. Advice medical explanatory label or similar stimulant carriage: average true answer percentage 
Table 3: Results according to medical care steps

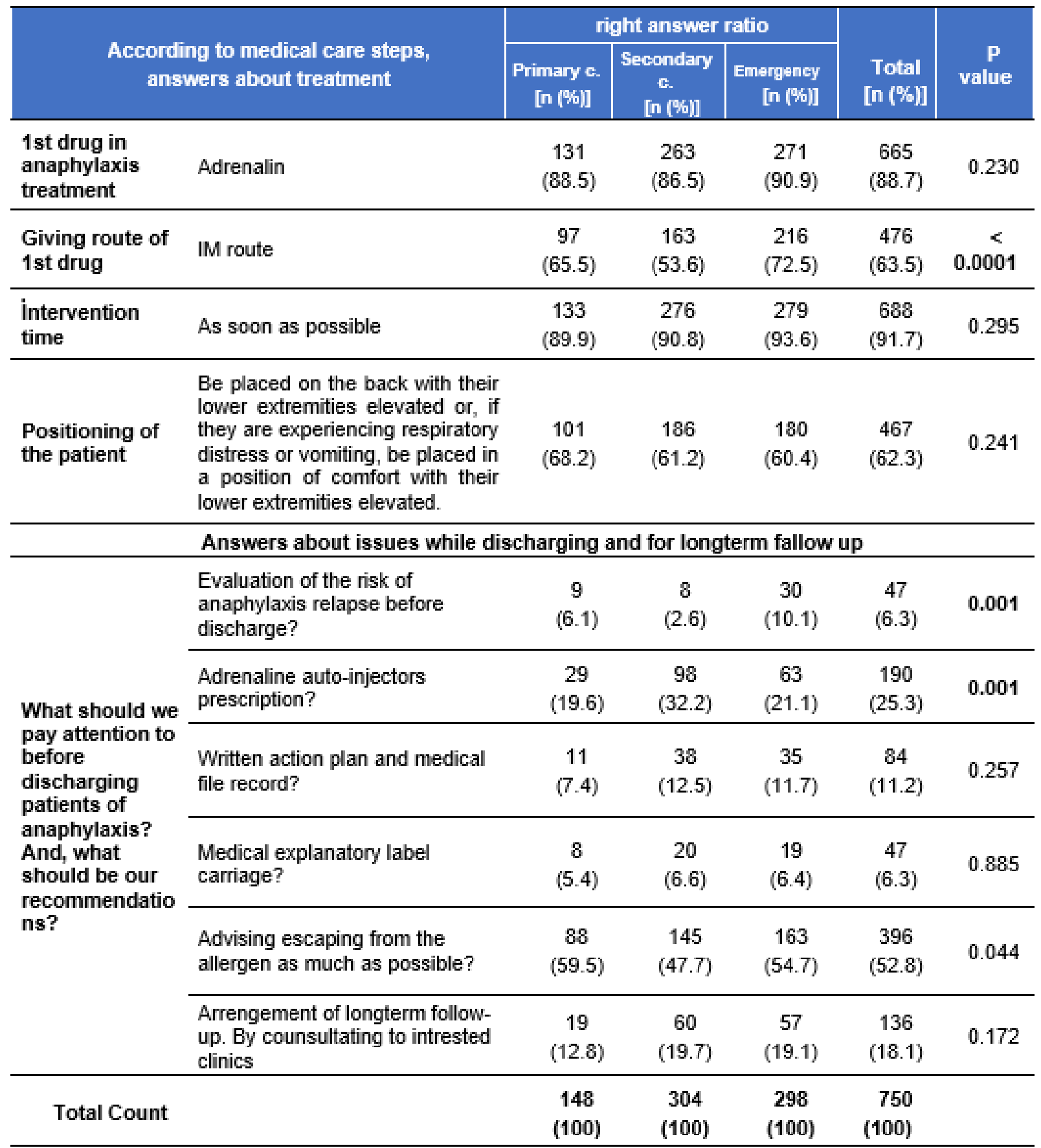

existence was found $6.3 \%$, groups true answer ratios were found similar each other $(\mathrm{p}=0.885)$.

9. Attention to the meas ures to reduce the risk (escaping from the allergen.): average true answer percentage existence was found $52.8 \%$, but groups true answer ratios were found significantly different from each other $(p=0.044)$. Highest true answer percentage was found among emergency doctors group (54.7\%).
10. Arrengement of longterm follow-up, by counsultating to intrested clinics: average true answer percentage existence was found $18.1 \%$, groups true answer ratios were found similar each other $(\mathrm{p}=$ $0.172)$

Total knowledge score index (KSI) was calculated nd the score was found to be $41.55 \pm 15.91$ (Table 2). Comparing KSI means according to care steps, the KSI was found significantly different among groups $(\mathrm{p}=$ 
0.011) (Table 4); but at all levels, an unacceptably low score was found for all doctors in general (Figure 3 ).We evaluated existence of any corelation between knowledge score index and Data from respondents, and it was found that there was no correlation; between

Table 4: Table knowledge score index between different care groups of doctors

\begin{tabular}{l|c|c|c}
\multicolumn{1}{c|}{ Specialty } & N & Mean \pm SD & p \\
\hline Primary care & 148 & $41.8919 \pm 15.17926$ & \\
\cline { 1 - 3 } Secondary care & 304 & $39.6053 \pm 16.28466$ & \multirow{2}{*}{0.011} \\
\cline { 1 - 3 } Emergency & 298 & $43.3557 \pm 15.70394$ & \\
\cline { 1 - 3 } Total & 750 & $41.5467 \pm 15.91054$ & \\
\hline
\end{tabular}

KSI and age of doctors ( $p>0.05$ ), between KSI and years in practice of doctors $(\mathrm{p}>0.05)$, and between KSI and having attended an episode of anaphylaxis.

There was significant difference found in mean KSI of doctor groups according to last update time of information about anaphylaxis $(\mathrm{p}<0.05)$ (Table 5).

\section{Discussion}

By evaluating the physician's level of knowledge, we tried to address some unmet needs in the management of anaphylaxis. We aimed to stress upon management between first intervention and discharge time especially after diagnosis, as suggested in international

Table 5: Mean KSI of doctor groups according to last update time of information about anaphylaxis

\begin{tabular}{|c|c|c|c|c|c|c|}
\hline \multirow{3}{*}{$\begin{array}{l}\text { Last update about } \\
\text { anaphylaxis }\end{array}$} & \multirow{3}{*}{$\mathbf{N}$} & \multicolumn{4}{|c|}{ Knowledge score index } & \multirow{3}{*}{$\begin{array}{c}\mathbf{p} \\
\text { value }\end{array}$} \\
\hline & & \multirow{2}{*}{ Mean \pm SD } & \multirow{2}{*}{$\begin{array}{l}\text { Std. } \\
\text { Error }\end{array}$} & \multicolumn{2}{|c|}{ 95\% Confidence Interval for Mean } & \\
\hline & & & & Lower Bound & Upper Bound & \\
\hline In the last $1 \mathrm{y}$ & 428 & $45.75 \pm 14.65$ & 0.71 & 44.36 & 47.14 & \multirow{4}{*}{0.001} \\
\hline In the last 2-3 y & 141 & $39.79 \pm 16.62$ & 1.40 & 37.02 & 42.56 & \\
\hline Over $3 y$ & 181 & $32.98 \pm 14.53$ & 1.08 & 30.85 & 35.11 & \\
\hline Total & 750 & $41.55 \pm 15.91$ & 0.58 & 40.41 & 42.69 & \\
\hline
\end{tabular}

Figure 3: Knowledge score index per participant

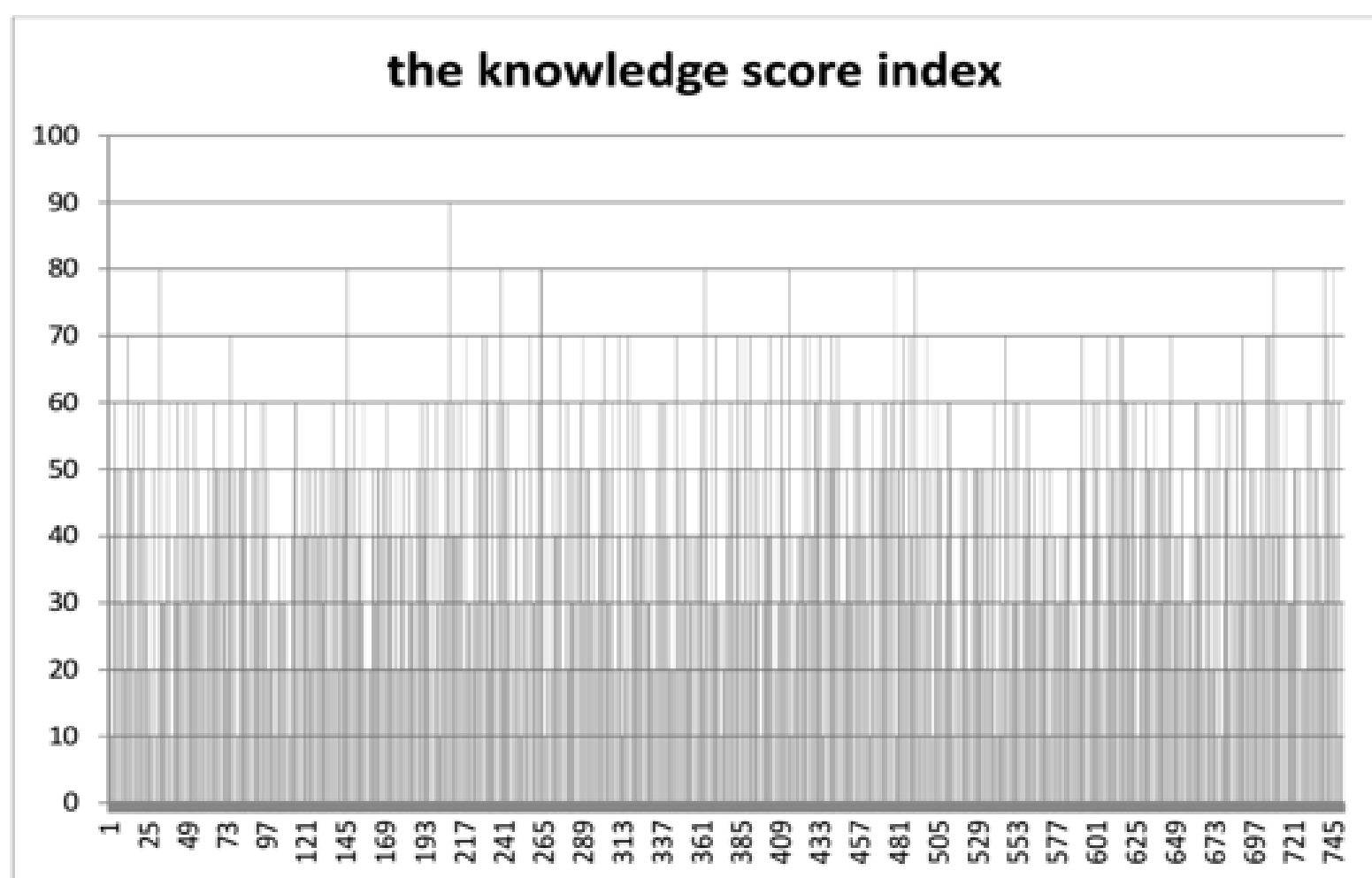


anaphylaxis guidelines. We aimed to focus on 'the supreme importance of making a prompt injection of epinephrine (adrenaline) intramuscularly', 'making proper position' and 'also emphasize 'preparation of the patient for self-treatment of anaphylaxis recurrence in the community, confirmation of anaphylaxis triggers, prescribing adrenaline auto-injector and prevention of recurrences through avoiding the trigger factors and carrying a warning card suggesting an urgent consultation with the specific clinic, and factors affecting this situation ${ }^{8,9}$ Our results demonstrate that there are significant knowledge gaps relating to management of anaphylaxis after first intervention among the doctors.

According to a 2013 study, although junior doctors' ability to manage anaphylaxis was somewhat improved compared to a similar study in a 2002 physician cohort, only one-third of them knew the correct dose and route for epinephrine administration. ${ }^{10}$ Recently in a 2020 study, a total of 120 physicians participated, the rate of correct answer about promptly choosing epinephrine as first drug of choice in treatment was $87.5 \% .{ }^{1}$ Similarly, in our study $88.7 \%$ of the participating physicians gave the correct answer about giving adrenalin as 1st choice in anaphylaxis as soon as possible. But about the route of administration, the ratio dropped to $66.7 \%$. The ratio of correct answers about the position droped to $62.7 \%$.

The incidence of rebound anaphylaxis is up to $20 \% .^{11}$ Patients should be observed in the emergency department for 4 to $24 \mathrm{~h}$ before discharge. Most biphasic responses occur during the first $8 \mathrm{~h}$, but it might be delayed up to $72 \mathrm{~h}$, and be fatal. ${ }^{12}$ There is no consensus on the optimal period of observation for a patient who has been treated for anaphylaxis. It is recommended that they be observed for 4 to $8 \mathrm{~h} .{ }^{4,13}$ Only $6.3 \%$ of participitating physicians underlied importance of bipahsic anaphylaxis evaluation before discharge.

Cooperation among ED and the allergist guarantee a quick and proper evaluation of the patients, providing comprehensive professional advice and instructions on how to minimize future exposure, suggesting specific preventive strategies, including pharmacologic prophylaxis and desensitization. The guidelines recommend a multi-step process for outpatient followup and management: self-injectable epinephrine prescription, allergen avoidance, written action plan, carrying medical explanatory card, and allergy clinic referral. $^{2,5,12}$

Despite relevant avoidance measures and immunomodulation, at least $30 \%$ of patients who survived an episode of anaphylaxis, experienced one or more recurrences. ${ }^{14}$ When this happens, it is impossible to predict whether the patient will die within minutes, respond to treatment, or recover spontaneously. Emergency preparedness focuses on carrying one or more adrenaline auto-injectors and having an anaphylaxis emergency action plan. ${ }^{13}$

It is well known that many patients receive either improper, inadequate or no instructions. All patients should receive auto-injector and training to use it immediately after future acute episodes before discharge. Althought epinephrine auto-injector was available in our country at the time of the study, and easy to reach, only $25.3 \%$ of our physicians opined that it should be prescribed before discharge. Also, only $11.2 \%$ of the physicians in the study were aware of the existence of an anaphylaxis action plan. Studies have shown that the presence and use of the written action plan increase the rates of both the correct diagnosis and treatment of the patients with anaphylaxis. ${ }^{6,9}$

Only $6.3 \%$ of the attending physicians suggested carrying a print card, $52.8 \%$ suggested avoiding triggering, and only $18.1 \%$ suggested that they be referred to the allergy clinic. ${ }^{15}$

It is well known that many patients receive improper or no instructions; failure to inject it promptly before a patient with anaphylaxis slips into acute cardiorespiratory failure and shock potentially increases the risk of death 10-13 times and potentially increases the risk of biphasic anaphylaxis in which initial symptoms resolve, only to recur 1 to $72 \mathrm{~h}$ later despite no further exposure to the trigger.

On rare occasions, epinephrine appears to be ineffective in anaphylaxis. Lack of efficacy might be due to a delay in epinephrine injection, suboptimal route or site of injection or low dose. ${ }^{16}$

Using the vital 10 questions, the average knowledge score calculated over 100 points was $41.54 \pm 15.91$. Doctors belonging to the tertiary care group received the highest score, but practically there was not much difference between them, we believe the results were unacceptably low for all groups. We noted that the most important factor is education regarding the 
scores. The score increased as the time to the last training on the subject decreased.

Most studies so far have focused on the diagnosis of anaphylaxis and the use of adrenaline. It is indisputable that the results obtained on these issues are vital. However, it should not be neglected that there are other factors affecting mortality in anaphylaxis. Unfortunately, there has been no change in the mortality rate caused by anaphylaxis over the years. This makes us think that our opinion might be correct and other issues might have been neglected in the approach to anaphylaxis. Our results also suggest that time lapse after training might be the most important factor in breaking this vicious circle.

\section{Limitations}

Our study only measured the theoretical knowledge levels of the attending physicians and cannot be expected to fully reflect what they will do when they encounter an emergency.

\section{Recommendations}

On the basis of the results of our study, we would like to offer the following recommendations; improving training of healthcare professionals for;

- Prompt identification of anaphylaxis triggers, symptoms, and signs, and the usefulness of adrenaline.

- Evaluation of the risk of anaphylaxis relapse before discharge.

- Prescribing adrenaline auto-injectors before discharge and train the patient in its use.

- Preparation of anaphylaxis action plan for the patients before discharge, including advising the patient to carry a medical explanatory label or card or similar stimulus, showing anaphylaxis triggers, symptoms, and signs, and the address, phone number of the preferred allergist / clinic / hospital to refer.

\section{Conclusion}

The results of our study data confirm that the treatment of anaphylaxis does not end with adrenalin use, and the level of awareness and knowledge of the healthcare staff about post-anaphylaxis management is largely inadequate. We need to run repeated reeducation programs for the healthcare staff on a regular basis to maintain their knowledge and skills at a satisfactory level.

\section{Conflict of interests}

The authors have no conflict of interest to declare.

\section{Authors'contribution}

OK, MI: Conduct of study, literature search, statistical analysis or manuscript editing

\section{References}

1. Tuncel T, Sancakli O, Bag O, Cetin HS, Özdoğru EE. Physicians' Approach to Anaphylaxis in Childhood. Ped Em Care. 2020. DOI: 10.1097/PEC.0000000000002064

2. Panesar S, Javad S, De Silva D, Nwaru B, Hickstein L, Muraro A, et al. The epidemiology of anaphylaxis in Europe: a systematic review. Allergy. 2013;68(11):135361. [PubMed] [Free Full Text] DOI: $10.1111 /$ all.12272

3. Simons FER, Ardusso LR, Bilò MB, El-Gamal YM, Ledford DK, Ring J, et al. World allergy organization guidelines for the assessment and management of anaphylaxis. World Allergy Organ J. 2011:4(2):13-37. [PubMed] [Free Full Text] DOI: 10.1097/WOX.0b013e318211496c

4. Lee S, Hess EP, Lohse C, Gilani W, Chamberlain AM, Campbell RL. Trends, characteristics, and incidence of anaphylaxis in 2001-2010: a population-based study. J Allergy Clin Immunol. 2017;139(1):182-188.e2. [PubMed] [Free Full Text] DOI: $\underline{\text { 10.1016/j.jaci.2016.04.029 }}$

5. Song TT, Lieberman P. Who needs to carry an epinephrine autoinjector. Cleve Clin J Med. 2019;86(1):66-72.DOI:10.3949/ccjm.86a.17123

6. Desai $\mathrm{SH}$, Jeong $\mathrm{K}$, Kattan JD, Lieberman $\mathrm{R}$, Wisniewski S, Green TD. Anaphylaxis management before and after implementation of guidelines in the pediatric emergency department. J Allergy Clin Immunol: In Practice. 2015;3(4):604-6. e2. DOI: 10.1016/j.jaip.2015.01.021

7. Pouessel G, Cerbelle V, Lejeune S, Leteurtre S, Ramdane N, Deschildre A, et al. Anaphylaxis admissions in pediatric intensive care units: Follow-up and risk of recurrence. Pediatr Allergy Immunol. 2019;30(3):341-347. [PubMed]

8. Simons FER, Ardusso LR, Bilò MB, Cardona V, Ebisawa $\mathrm{M}$, El-Gamal YM, et al. International consensus on (ICON) anaphylaxis. World Allergy Organ J. 2014;7(1):9. [PubMed] [Free Full Text] DOI: $10.1186 / 1939-4551-7-9$

9. Arroabarren E, Lasa E, Olaciregui I, Sarasqueta C, Munoz J, Pérez-Yarza E. Improving anaphylaxis 
management in a pediatric emergency department. Pediatr Allergy Immunol. 2011;22(7):708-714. [PubMed] DOI: 10.1111/j.1399-3038.2011.01181.x

10. Plumb B, Bright P, Gompels MM, Unsworth DJ. Correct recognition and management of anaphylaxis: not much change over a decade. Postgraduate Med J. 2015;91(1071):3-7. [Free Full Text] DOI: $\underline{10.1136 / \text { postgradmedj-2013-132181 }}$

11. Pumphrey RS, Gowland MH. Further fatal allergic reactions to food in the United Kingdom, 1999-2006. J Allergy Clin Immunol. 2007;119(4):1018-1019. [PubMed] DOI:10.1016/j.jaci.2007.01.021

12. Sidhu N, Jones S, Perry T, Thompson T, Storm E, Castro MSM, et al. Evaluation of anaphylaxis management in a pediatric emergency department. Pediatr Emerg Care. 2016;32(8):508-513. [PubMed] DOI: $10.1097 / P E C .0000000000000864$
13. Tupper J, Visser S. Anaphylaxis: A review and update. Can Fam Physician. 2010;56(10):1009-1011. [PubMed] [Free Full Text]

14. Tejedor-Alonso M A, Moro-Moro M, Múgica-García MV. Epidemiology of Anaphylaxis: Contributions From the Last 10 Years. J Investig Allergol Clin Immunol. 2015;25(3):163-175. [PubMed] [Free Full Text]

15. Alvarez-Perea A, Tanno LK, Baeza ML. How to manage anaphylaxis in primary care. Clin Transl Allergy. 2017;7:45. [PubMed] [Free Full Text] DOI: $\underline{10.1186 / \mathrm{s} 13601-017-0182-7}$

16. Simons FE. Anaphylaxis: Recent advances in assessment and treatment. J Allergy Clin Immunol. 2009;124(4):625-36; quiz 637-8. [PubMed] DOI: $10.1016 /$ j.jaci.2009.08.025 